\title{
Exercise-induced modulation of cardiac lipid content in healthy lean young men
}

\author{
L. Bilet $\cdot$ T. van de Weijer $\cdot$ M. K. C. Hesselink • \\ J. F. C. Glatz $\cdot$ H. J. Lamb $\cdot$ J. Wildberger $\cdot$ M. E. Kooi • \\ P. Schrauwen $\cdot$ V. B. Schrauwen-Hinderling
}

Received: 18 October 2010/Revised: 17 November 2010/Accepted: 13 December 2010/Published online: 23 December 2010

(C) The Author(s) 2010. This article is published with open access at Springerlink.com

\begin{abstract}
Cardiac lipid accumulation is associated with decreased cardiac function and energy status (PCr/ATP). It has been suggested that elevated plasma fatty acid (FA) concentrations are responsible for the cardiac lipid accumulation. Therefore, the aim of the present study was to investigate if elevating plasma FA concentrations by exercise results in an increased cardiac lipid content, and if this influences cardiac function and energy status. Eleven male subjects (age $25.4 \pm 1.1$ years, BMI $23.6 \pm 0.8 \mathrm{~kg} / \mathrm{m}^{2}$ )
\end{abstract}

L. Bilet · T. van de Weijer - M. K. C. Hesselink .

M. E. Kooi · P. Schrauwen · V. B. Schrauwen-Hinderling

NUTRIM, School of Nutrition, Toxicology and Metabolism,

Maastricht University Medical Center, Maastricht,

The Netherlands

L. Bilet · T. van de Weijer $\cdot$ P. Schrauwen $(\bowtie)$

Department of Human Biology, Maastricht University Medical Center, P.O. Box 616, 6200 MD Maastricht, The Netherlands

e-mail: p.schrauwen@maastrichtuniversity.nl

M. K. C. Hesselink

Department of Human Movement Sciences, Maastricht

University Medical Center, Maastricht, The Netherlands

J. F. C. Glatz

Department of Molecular Genetics, Maastricht University

Medical Center, Maastricht, The Netherlands

H. J. Lamb

Department of Radiology, Leiden University Medical Center, Leiden, The Netherlands

J. Wildberger · M. E. Kooi · V. B. Schrauwen-Hinderling Department of Radiology, Maastricht University Medical Center, Maastricht, The Netherlands

M. E. Kooi

Cardiovascular Research Institute Maastricht, Maastricht

University Medical Center, Maastricht, The Netherlands performed a 2-h cycling protocol, once while staying fasted and once while ingesting glucose, to create a state of high versus low plasma FA concentrations, respectively. Cardiac lipid content was measured by proton magnetic resonance spectroscopy $\left({ }^{1} \mathrm{H}-\mathrm{MRS}\right)$ at baseline, directly after exercise and again $4 \mathrm{~h}$ post-exercise, together with systolic function (by multi-slice cine-MRI) and cardiac energy status (by ${ }^{31} \mathrm{P}-\mathrm{MRS}$ ). Plasma FA concentrations were increased threefold during exercise and ninefold during recovery in the fasted state compared with the glucose-fed state $(p<0.01)$. Cardiac lipid content was elevated at the end of the fasted test day (from $0.26 \pm 0.04$ to $0.44 \pm$ $0.04 \%, p=0.003$ ), while it did not change with glucose supplementation (from $0.32 \pm 0.03$ to $0.26 \pm 0.05 \%$, $p=0.272$ ). Furthermore, PCr/ATP was decreased by $32 \%$ in the high plasma FA state compared with the low FA state $(n=6, p=0.014)$. However, in the high FA state, the ejection fraction $4 \mathrm{~h}$ post-exercise was higher compared with the low FA state $(63 \pm 2$ vs. $59 \pm 2 \%, p=$ 0.018). Elevated plasma FA concentrations, induced by exercise in the fasted state, lead to increased cardiac lipid content, but do not acutely hamper systolic function. Although the lower cardiac energy status is in line with a lipotoxic action of cardiac lipid content, a causal relationship cannot be proven.

Keywords Magnetic resonance spectroscopy - Cardiac lipid content - Cardiac energy status - Cardiac function . Plasma (free) fatty acids $\cdot$ Exercise

\section{Introduction}

Hospitalization for congestive heart failure is increasing worldwide [20]. This increase is associated with the 
increasing prevalence of obesity $[6,10]$, which is an independent risk factor for the development of heart failure [11]. Obesity is associated with excessive storage of lipids (triglycerides) not only in adipose tissue but also in skeletal muscle, the liver and the heart. It has been suggested that lipid accumulation in cardiac tissue may have lipotoxic effects, thereby hampering cardiac function and predisposing to cardiomyopathy and heart failure. Cardiac lipotoxicity is well documented in both obese $[31,36]$ and lean animal models with exaggerated storage of fat in cardiac muscle induced by targeted over expression of genes involved in lipid delivery and synthesis in the myocardium [1-3, 17, 35], but direct evidence for cardiac lipotoxicity in humans is scarce. However, proton magnetic resonance spectroscopy $\left({ }^{1} \mathrm{H}-\mathrm{MRS}\right)$ has recently been proven reliable for non-invasive in vivo investigation of cardiac tissue and enables human interventional studies [29, 32]. Such studies have indicated that cardiac lipid accumulation is elevated in conditions of increased circulating fatty acid (FA) concentrations, such as obesity [5], a very low calorie diet [33] and fasting [18], and circulating FA concentrations were found to correlate with cardiac lipid content [5]. These data suggest that the cardiac uptake of FA is not tightly matched to oxidational needs but rather follows circulating FA concentrations. In addition, it has been shown that high plasma FA concentrations correlate negatively with the energy status of the heart [21], and the latter has a strong prognostic value in heart failure patients and might be an early marker of disturbed cardiac metabolism [16].

In that respect, it is interesting to examine the effect of acute exercise on cardiac lipid content and function. Acute exercise-when performed in the fasting state-is associated with a threefold elevation of plasma FA concentrations [22]. However, when acute exercise is performed while providing carbohydrate beverages, the increase in FA can be completely blunted. It could be hypothesized that cardiac lipid content will increase during exercise performed in the fasting state, due to elevated plasma FA concentrations. On the other hand, lipid content in skeletal muscle can be lowered by prolonged acute exercise [24] even despite high circulatory FA concentrations, due to increased fat oxidation to fuel physical activity. We have recently shown that prolonged endurance training decreased cardiac lipid content in parallel with improvements in cardiac function [23]. Thus, it can also be hypothesized that cardiac fat content will decrease during exercise due to an increased oxidation of FA needed to meet the increased cardiac work. Therefore, comparing the effect of acute exercise with high versus low circulating FA concentrations will allow us to test the hypothesis that physiologically induced elevation of plasma FA concentrations lead to an unrestricted uptake of FA in cardiac tissue, subsequent accumulation of intracardiac fat, and an ultimate reduction in cardiac function and cardiac energy status. To this end, we employed ${ }^{1} \mathrm{H}$-MRS to determine cardiac lipid content before and after exercise as well as $4 \mathrm{~h}$ post-exercise. MRI and ${ }^{31} \mathrm{P}$-MRS were employed $4 \mathrm{~h}$ post-exercise to determine cardiac function and cardiac energy status, respectively.

\section{Materials and methods}

\section{Subjects}

Eleven healthy lean, untrained young men participated in this study. Subjects' characteristics are shown in Table 1. None of the subjects participated in competitive sports, and subjects with unstable weight $(>3 \mathrm{~kg}$ change in preceding 6 months) were excluded from the study. The institutional medical ethical committee approved the study, and written informed consent was obtained from all participants.

\section{Study protocol}

Before the start of the study, body composition and maximal aerobic capacity was determined in all subjects. The experimental trial comprised two separate test days. Subjects refrained from physical activity 2 days prior to the test days. Furthermore, subjects were instructed to consume a standardized meal the evening prior to the test days and stay fasted from $10 \mathrm{pm}$ onwards. On the test days, subjects came to the laboratory at 7:00 am after an overnight fast. Cardiac lipid content was investigated by ${ }^{1} \mathrm{H}$-MRS. After this, a Teflon canula was inserted into an antecubital vein for sampling of blood. Immediately after taking the first blood sample, subjects ingested $1.4 \mathrm{~g} / \mathrm{kg}$ bodyweight of glucose (dissolved in water to a $20 \%$ solution and flavored with $1 \mathrm{ml}$ lemon juice) or the same amount of water on the test day in fasted state. Next, subjects were guided to another lab where they started exercising at $50 \%$ of their maximal power output $(t=0 \mathrm{~min})$. The exercise period lasted for $2 \mathrm{~h}$, and during exercise blood samples were taken, and substrate oxidation was measured by indirect calorimetry for $15 \mathrm{~min}$ (Omnical, Maastricht, The

Table 1 Subjects' characteristics

\begin{tabular}{ll}
\hline Subjects' characteristics & Mean \pm SE \\
\hline Age $($ years $)$ & $25.4 \pm 1.1$ \\
Height $(\mathrm{m})$ & $1.79 \pm 0.02$ \\
Weight $(\mathrm{kg})$ & $75.8 \pm 3.5$ \\
$\mathrm{BMI}\left(\mathrm{kg} / \mathrm{m}^{2}\right)$ & $23.6 \pm 0.8$ \\
Fat $(\%)$ & $18.3 \pm 2.0$ \\
$V \mathrm{O}_{2 \max } / \mathrm{kg}\left(\mathrm{ml} \times \mathrm{min}^{-1} \times \mathrm{kg}^{-1}\right)$ & $45.9 \pm 2.2$ \\
\hline
\end{tabular}


Netherlands) every $30 \mathrm{~min}$ (at $t=30,60,90$ and $120 \mathrm{~min}$ ). Immediately after cessation of the $2 \mathrm{~h}$ of exercise, a second ${ }^{1} \mathrm{H}-\mathrm{MRS}$ measurement was performed. Subsequently, subjects bed-rested for $3 \mathrm{~h}$, and a third ${ }^{1} \mathrm{H}-\mathrm{MRS}$ scan together with additional measurements of ejection fraction (by CINE$\mathrm{MRI}$ ) and cardiac energy status (by ${ }^{31} \mathrm{P}-\mathrm{MRS}$ ) were started $4 \mathrm{~h}$ after exercise. During this post-exercise period, blood samples were taken, and substrate oxidation was measured for $15 \mathrm{~min}$ every hour (at $t=180,240,300$ and $360 \mathrm{~min}$ ). The experimental design is depicted in Fig. 1.

The entire protocol was performed twice: once with the ingestion of glucose $(0.35 \mathrm{~g} / \mathrm{kg}$ bodyweight at $t=-15$, $30,60,90,180,240,300$ and 360) after the initial bolus of $1.4 \mathrm{~g} / \mathrm{kg}$ of bodyweight and once in the fasted state with ingestion of equal amounts of water. Both test days were separated by at least 1 week and were performed in random order. On a separate day, a reference measurement of cardiac function without prior exercise was performed in the morning after an overnight fast.

Maximal oxygen uptake (whole body oxidative capacity)

A routine incremental cycling test was used to determine maximal aerobic capacity as described previously [8]. Briefly, after a warming-up period of $5 \mathrm{~min}$, the intensity was increased every $2.5 \mathrm{~min}$ until exhaustion. Oxygen consumption was measured continuously throughout the test using indirect calorimetry (Omnical, Maastricht, The Netherlands) to determine $\mathrm{VO}_{2 \max }$.

\section{Hydrostatic weighing}

Hydrostatic weighing with simultaneous measurement of lung volume was used to determine body composition in the morning in the fasted state. The equation of Siri [28] was used to calculate fat percentage, fat mass and fat-free mass.

Blood sample analysis

Blood samples were collected in EDTA-containing tubes and immediately centrifuged at high speed and frozen in liquid nitrogen and thereafter stored at $-80^{\circ} \mathrm{C}$ until assayed. Plasma fatty acids, triglycerides and glucose were measured with enzymatic assays automated on a Cobas Fara/Mira (FA: Wako Nefa C test kit, Wako Chemicals, Neuss, Germany) (glucose: hexokinase method, Roche, Basel, Switzerland) (triglycerides: ABX Pentra CP reagents, Horiba ABX Diagnostics, Montpellier, France) (glycerol: Enzytec ${ }^{\mathrm{TM}}$ glycerol kit, R-Biopharm, Germany).

\section{MRI}

Cardiac CINE-MRI examinations were performed on a whole body MRI-scanner (Intera, 1.5 T, Philips Healthcare, Best, The Netherlands) as reported previously [32]. At the end of the test day, slices covering the whole left ventricle were acquired in 24 heart phases to determine parameters of systolic function. During the other measurements, only four slices were acquired, which was sufficient to guide spectroscopy.

Image processing

All images were analyzed quantitatively, and ten images were examined for inter-observer reliability using dedicated software (CAAS, Pie Medical Imaging, Maastricht, The Netherlands) to determine end diastolic and end systolic volumes, left ventricular stroke volume, ejection fraction, cardiac output and cardiac index.

\section{${ }^{1} \mathrm{H}-\mathrm{MRS}$}

Cardiac lipid content was determined in vivo by ${ }^{1} \mathrm{H}$-MRS as reported previously [23]. Respiratory gating and tracking was performed with a pencil beam navigator placed on the diaphragm [32]. Chemical shift selective (CHESS) water suppression was performed to acquire spectra of the lipid metabolites using a series of 32 spectra ( $n=2$ each), resulting in a total of 64 acquisitions. To acquire a reference spectrum of the unsuppressed water peak in the same volume of interest, the acquisition was repeated, with the CHESS pulse off resonance, using a series of 12 spectra ( $n=2$ each), resulting in a total of 24 acquisitions. From 11 subjects, 2 had to be excluded from the cardiac lipid content analysis due to poor quality of spectra.
Fig. 1 Experimental design of the study. All subjects performed the protocol two times, one time in the fasted state consuming water and one time with glucose supplementation. MRS cardiac magnetic resonance spectroscopy

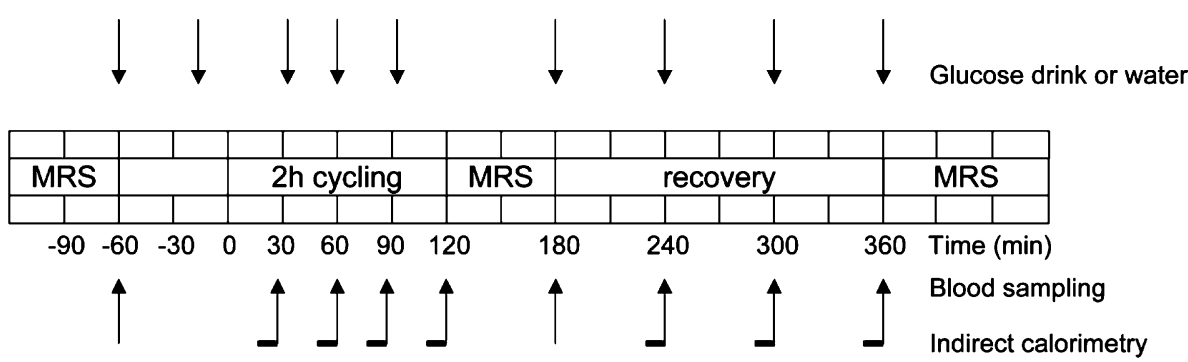


${ }^{1} \mathrm{H}-\mathrm{MRS}$ spectral post-processing

Post-processing of the spectra was performed with the jMRUI software [7]. All ${ }^{1} \mathrm{H}$ MR spectroscopic data were fitted in the time domain. Manual phase correction was performed, and subsequently, all spectra with water suppression and without were averaged, resulting in one watersuppressed lipid spectrum originating from 128 averages and a non-suppressed spectrum from 24 averages for quantification of the water resonance. Myocardial lipid peaks were fitted by using the Advanced magnetic resonance (AMARES) fitting algorithm [34] within the jMRUI software [15] as reported earlier [32]. Cardiac lipid content is given as the percentage of the $\mathrm{CH}_{2}$ peak compared to the water resonance, uncorrected for $\mathrm{T} 1$ and $\mathrm{T} 2$ relaxation.

\section{${ }^{31} \mathrm{P}-\mathrm{MRS}$}

Single voxel cardiac ${ }^{31} \mathrm{P}-\mathrm{MRS}$ spectra were obtained from the left ventricle with subjects in the supine position as reported previously [9]. A $10 \mathrm{~cm}$ coil was fixed on the chest, at the level of the myocardium. Manual tuning and matching of the ${ }^{31} \mathrm{P}$-surface coil was performed to adjust for different coil loadings. ECG-triggered ISIS was used for localization to the left ventricle $(\mathrm{TR}=3.6 \mathrm{~s}$, $n=192$ ). Spectroscopy and shimming volumes were planned on the transverse and sagittal scout images to include the entire left ventricle, while avoiding chest wall muscle and diaphragm muscle. A rest slab was placed over the chest muscle to minimize contamination from skeletal muscle.

${ }^{31} \mathrm{P}-\mathrm{MRS}$ spectral post-processing

${ }^{31} \mathrm{P}-\mathrm{MRS}$ was quantified with the dedicated software jMRUI. Signals were quantified in the time domain. Six
Gaussian peaks were fitted using prior knowledge defining chemical shift. The ATP level in the ${ }^{31} \mathrm{P}-\mathrm{MRS}$ was corrected for the ATP contribution from blood and $\mathrm{T}_{1}$ corrected [4].

\section{Statistics}

Data are presented as mean \pm SE. A two-way ANOVA for repeated measures was performed to analyze data over time for cardiac lipid content, substrate oxidation and plasma values of FA, glucose, triglycerides and glycerol. Statistical differences in ejection fraction and PCr/ATP between the two conditions were determined by a paired Student $t$ test. All statistics were performed using SPSS 16.0 for Mac, and $p<0.05$ was considered statistically significant.

\section{Results}

Energy expenditure and substrate oxidation

No significant differences in energy expenditure between the glucose-fed and the fasted state were found neither during exercise nor during post-exercise (see Table 2). During exercise, there was a significant time $(p<0.01)$ and treatment $(p<0.01)$ effect for respiratory quotient $(\mathrm{RQ})$, without a time $\times$ treatment interaction $(p=0.39)$ effect. RQ was significantly higher at all time points in the glucose-fed state compared with the fasted state $(p<0.01)$ (see Fig. 2a), reflecting higher carbohydrate oxidation in glucose-fed state, and RQ decreased between $t=30$ and $t=90 \mathrm{~min}(p<0.05)$ in both conditions. In the postexercise period, a significant treatment effect $(p<0.01)$ was revealed, but no time $(p=0.88)$ or time $\times$ treatment $(p=0.10)$ effects were present. Also under resting conditions post-exercise, RQ was significantly higher in the

Table 2 Energy expenditure and fat and carbohydrate oxidation during and after exercise in glucose-supplemented and fasted states

\begin{tabular}{|c|c|c|c|c|c|c|c|}
\hline \multirow[t]{2}{*}{ Treatment } & \multirow[t]{2}{*}{ Time $(\min )$} & \multicolumn{3}{|l|}{ Glucose } & \multicolumn{3}{|l|}{ Fasted } \\
\hline & & $\mathrm{EE}(\mathrm{kJ} / \mathrm{min})$ & $\begin{array}{l}\text { Fat oxidation } \\
(\mathrm{mg} / \mathrm{min})\end{array}$ & $\begin{array}{l}\text { CHO oxidation } \\
(\mathrm{mg} / \mathrm{min})\end{array}$ & $\mathrm{EE}(\mathrm{kJ} / \mathrm{min})$ & $\begin{array}{l}\text { Fat oxidation } \\
(\mathrm{mg} / \mathrm{min})\end{array}$ & $\begin{array}{l}\text { CHO oxidation } \\
(\mathrm{mg} / \mathrm{min})\end{array}$ \\
\hline \multirow[t]{4}{*}{ Exercise } & 30 & $41.9 \pm 1.5$ & $313 \pm 31 *$ & $1,871 \pm 80 *$ & $41.7 \pm 1.6$ & $476 \pm 83$ & $1,451 \pm 151$ \\
\hline & 60 & $41.9 \pm 1.2$ & $398 \pm 27^{\#}$ & $1,659 \pm 73^{\#}$ & $42.0 \pm 1.3$ & $530 \pm 31$ & $1,336 \pm 88$ \\
\hline & 90 & $42.3 \pm 1.4$ & $469 \pm 27^{\#}$ & $1,503 \pm 67^{\#}$ & $42.3 \pm 1.5$ & $635 \pm 16$ & $1,092 \pm 85$ \\
\hline & 120 & $43.8 \pm 1.9$ & $467 \pm 3^{\#}$ & $1,606 \pm 137^{\#}$ & $42.5 \pm 1.8$ & $665 \pm 22$ & $1,026 \pm 124$ \\
\hline \multirow[t]{3}{*}{ Post-exercise } & 240 & $5.3 \pm 0.2$ & $45 \pm 8^{\#}$ & $226 \pm 19^{\#}$ & $5.5 \pm 0.2$ & $95 \pm 7$ & $109 \pm 11$ \\
\hline & 300 & $5.4 \pm 0.2$ & $30 \pm 5^{\#}$ & $267 \pm 17^{\#}$ & $5.5 \pm 0.2$ & $103 \pm 5$ & $93 \pm 11$ \\
\hline & 360 & $5.4 \pm 0.2$ & $30 \pm 6^{\#}$ & $269 \pm 18^{\#}$ & $5.6 \pm 0.2$ & $104 \pm 6$ & $92 \pm 11$ \\
\hline
\end{tabular}

Data are means \pm SEM

$E E$ energy expenditure, $\mathrm{CHO}$ carbohydrate

$* p<0.05$ and ${ }^{\#} p<0.01$ compared with fasted treatment 


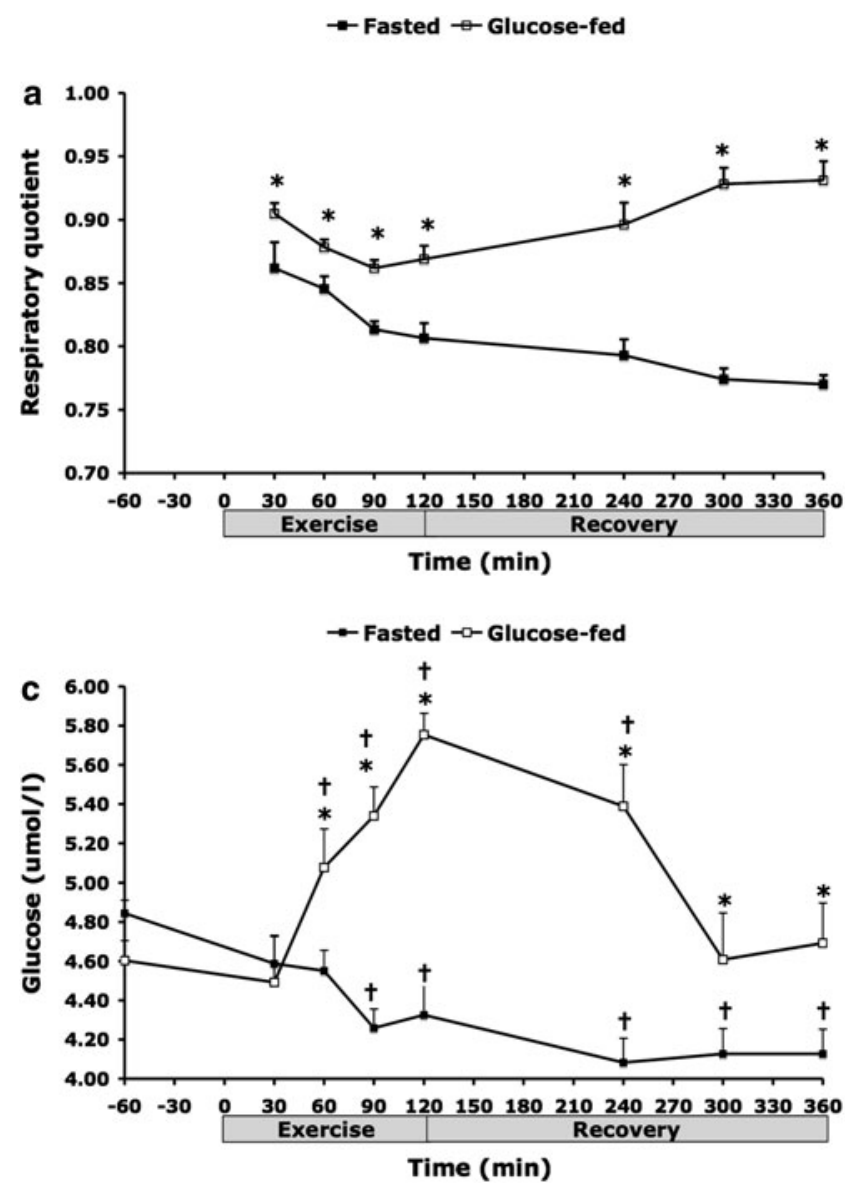

Fig. 2 a Respiratory quotient during and after $2 \mathrm{~h}$ of cycling at $50 \%$ of maximal power output (Wmax) and plasma concentrations of b (free) fatty acids (FA), c glucose and $\mathbf{d}$ triglyceride (TG), with (open square) and without (filled square) glucose supplementation.

glucose-fed state compared with the fasted state at all time points $(<0.01)$.

During exercise, there was a significant time $(p<0.01)$ and treatment $(p<0.01)$ effect for both carbohydrate and fat oxidation, without a time $\times$ treatment interaction ( $p=0.38$ and 0.27 , respectively) effect. As depicted in Table 2, carbohydrate oxidation was significantly higher at all time points in the glucose-fed state compared with the fasted state $(p<0.01)$, whereas fat oxidation was significantly higher at all time points in the fasted state compared with the glucose-fed state $(p<0.05)$. Both carbohydrate and fat oxidation increased between $t=30$ and $t=90$ $(p<0.01)$. In the post-exercise period, the carbohydrate oxidation was significantly higher in the glucose-fed state compared with the fasted state at all time points $(p<0.01)$, whereas the fat oxidation was significantly higher in the fasted state compared with the glucose-fed state at all time points $(p<0.01)$. There was no time or time $\times$ treatment interaction effect for neither carbohydrate nor fat oxidation in the post-exercise period $(p>0.05)$.
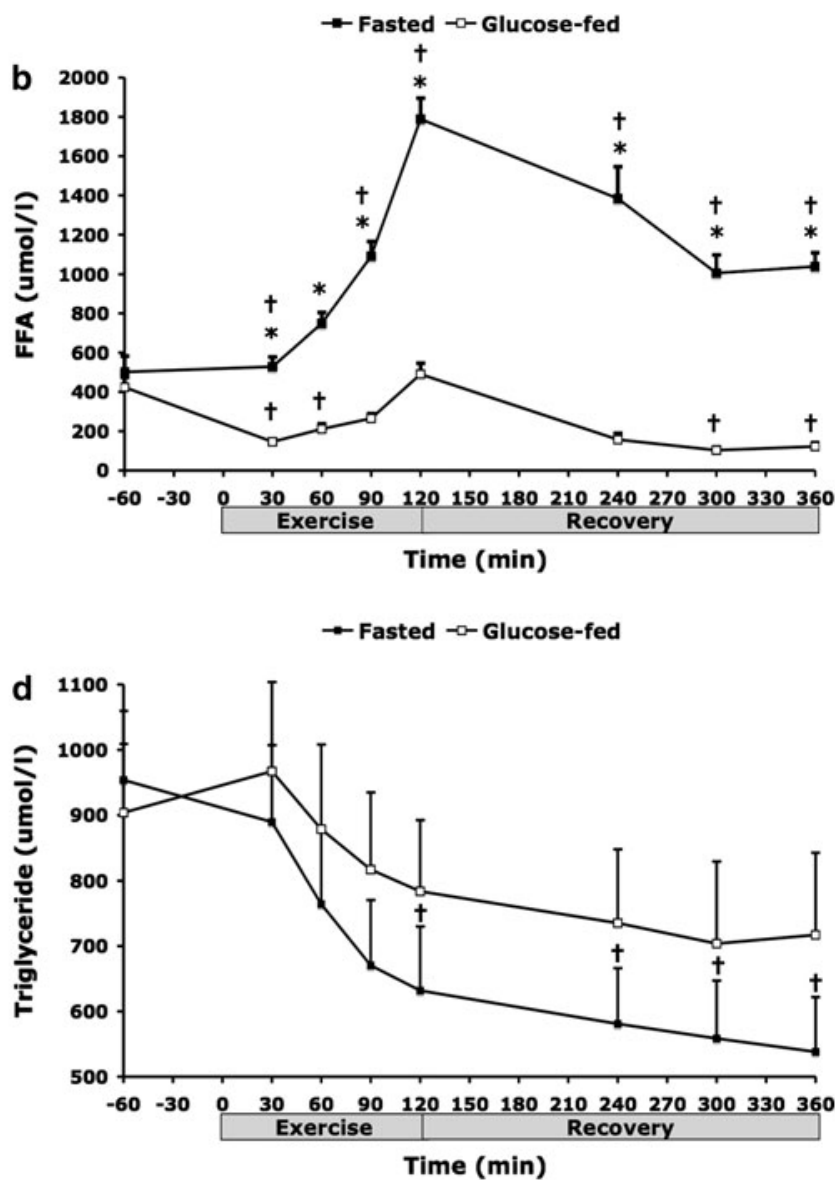

a-d $* p<0.01$ compared with glucose-supplemented condition. a-d ${ }^{\dagger} p<0.05$ changes over time compared with baseline $(t=-60)$. Data are mean $\pm \mathrm{SE}$

Blood plasma concentrations

During exercise, there was a significant time $(p<0.01)$, treatment $(p<0.01)$ and time $\times$ treatment interaction $(p<0.01)$ effect for plasma FA concentrations. Except for baseline $(t=0)$, plasma FA concentrations were higher at all time points during exercise in the fasted state $(p<0.01)$ compared with the glucose-fed state (Fig. 2b). Plasma FA concentrations increased with time during exercise $(p<0.01)$, with this increase being more pronounced in the fasted state compared to the glucose-fed state. In the post-exercise period, plasma FA concentrations were higher at all time points in the fasted state compared with the glucose-fed state $(p<0.001)$, but there was no time or time $\times$ treatment interaction effect.

During exercise, there was a significant time $(p<0.05)$, treatment $(p<0.01)$ and time $\times$ treatment interaction $(p<0.01)$ effect for plasma glucose concentrations. In the fasted state, plasma glucose concentrations decreased during exercise (Fig. 2c), whereas an increase 
was observed in the glucose-fed state. As a result, plasma glucose levels were higher in the glucose-fed state compared with the fasted state from time point $t=60 \mathrm{~min}$ onwards $(p<0.05)$. In the post-exercise period, plasma glucose concentrations were higher at all time points in the glucose-fed state compared with the fasted state $(p<0.01)$, and there was a time $\times$ treatment interaction ( $p=0.046)$ effect, but there was no time $(p=0.085)$ effect.

During exercise, there was no significant time $(p=0.16)$, treatment $(p=0.22)$ or time $\times$ treatment interaction $(p=0.87)$ effect for plasma triglyceride concentrations, whereas there was a tendency to higher plasma triglyceride concentrations post-exercise in the glucose-fed state compared with the fasted state ( $p=0.069$; Fig. 2d). There was no time $(p=0.95)$ or time $\times$ treatment interaction $(p=0.99)$ effect for plasma triglyceride concentrations post-exercise. Considering all time points of the test day, there is an overall time effect with triglyceride concentrations decreasing over time, being significantly different from baseline levels in the fasted condition from $t=120$ min onwards $(p>0.05)$.

There was a significant time $(p<0.01)$, treatment $(p<0.01)$ and time $\times$ treatment interaction $(p<0.01)$ effect for glycerol during exercise. Glycerol concentrations were higher in the fasted state, and increased during exercise, with a more pronounced increase in the fasted state (from $99 \pm 14$ to $620 \pm 31 \mu \mathrm{mol} / \mathrm{l}$ in the fasted state vs. $91 \pm 9$ to $219 \pm 27 \mu \mathrm{mol} / 1$ in the glucose-fed state). Post-exercise glycerol was significantly higher in the fasted state compared with the glucose-fed state $(135 \pm 9$ vs. $46 \pm 3 \mu \mathrm{mol} / \mathrm{l}$ at $t=360)(p<0.01)$, but there was no time $(0.11)$ or time $\times$ treatment interaction $(p=0.22)$ effect.

\section{Cardiac lipid content}

There was a significant treatment $(p=0.029)$ and time $\times$ treatment interaction $(p=0.009)$ effect for cardiac lipid content, but no time $(p=0.242)$ effect. As depicted in Fig. 3, overall cardiac lipid content was higher at the end of the test day in the fasted state compared with the glucose-fed state, and cardiac lipid content increased after recovery from exercise in the fasted state $(p=0.003)$, whereas it did not change when glucose supplementation was given $(p=0.272)$. At baseline, there were no differences in cardiac lipid content between the two conditions $(p=0.239)$. Cardiac lipid content was also not different between the two conditions directly after exercise $(p=0.119)$. However, $4 \mathrm{~h}$ post-exercise cardiac lipid content was elevated by $41 \%$ in the fasted state compared with the glucose-fed state $(p=0.008)$.

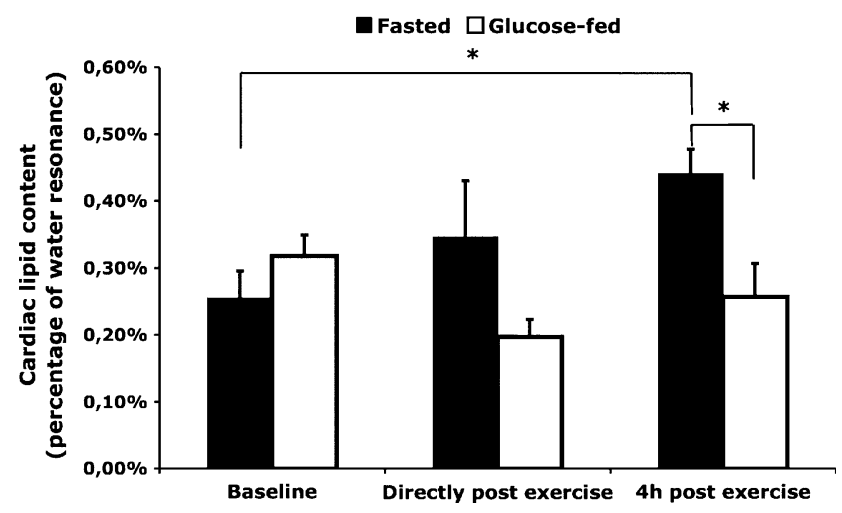

Fig. 3 Cardiac lipid content at baseline, directly post-exercise and $4 \mathrm{~h}$ post-exercise. Cardiac lipid content is expressed as the relative intensity of the $\mathrm{CH}_{2}$ peak, compared to the unsuppressed water resonance. $n=9, * p<0.01$. Data are mean $\pm \mathrm{SE}$

Cardiac energy status and function

In a subgroup of six subjects, PCr/ATP was determined $4 \mathrm{~h}$ post-exercise. PCr/ATP was $32 \%$ lower in the fasted state compared with the glucose-fed state $(p=0.014$; Fig. 4). Ejection fraction $(p=0.038$; Fig. 5), stroke volume (115 \pm 6 vs. $107 \pm 4 \mathrm{ml}, p=0.044)$, cardiac output $(7.2 \pm 0.5$ vs. $6.0 \pm 0.2 \mathrm{l} / \mathrm{min}, p=0.016)$ and cardiac index ( $3.9 \pm 0.3$ vs. $\left.3.3 \pm 0.2 \mathrm{l} / \mathrm{min} / \mathrm{m}^{2}, p=0.016\right)$ were all significantly higher at $4 \mathrm{~h}$ of recovery in the fasted state compared with the glucose-fed state. At $4 \mathrm{~h}$ of recovery, end diastolic $(182 \pm 8 \mathrm{ml}$ in the fasted state vs. $180 \pm$ $8 \mathrm{ml}$ in the glucose-fed state, $p=0.626$ ) and end systolic ( $68 \pm 4 \mathrm{ml}$ in the fasted state vs. $73 \pm 5 \mathrm{ml}$ in the glucose-fed state, $p=0.179$ ) volumes were not significantly different between the fasted and glucose-fed states. A tendency to a higher heart rate during these measurements in the fasted state was found, compared with the glucosefed state; however, it did not reach statistical significance ( $63 \pm 3$ vs. $58 \pm 3$ bpm, $p=0.097$ ). Inter-observer variability of ejection fraction analysis was good with a coefficient of variation of $3.6 \pm 0.9 \%$.

To compare the values for cardiac function at $4 \mathrm{~h}$ of recovery to baseline reference values without prior exercise, we measured, in the same subjects, cardiac function after an overnight fast, on a separate day. $4 \mathrm{~h}$-recovery values for ejection fraction $(p=0.026$; Fig. 5), cardiac output $(7.2 \pm 0.5$ vs. $5.8 \pm 0.3 \mathrm{ml}, n=9, p=0.015)$ and cardiac index $\left(3.7 \pm 0.3\right.$ vs. $\left.3.0 \pm 0.2 \mathrm{l} / \mathrm{min} / \mathrm{m}^{2}, n=9, p=0.007\right)$ were all significantly higher in the fasted state compared with the reference measurement, whereas the glucose-fed state did not differ from the reference measurement $(p>0.05)$. There was no difference in stroke volume between the reference measurement and the fasted $(p=0.933)$ or the glucose-fed $(p=0.241)$ states. Heart rate was significantly lower during the reference measurement compared with both 


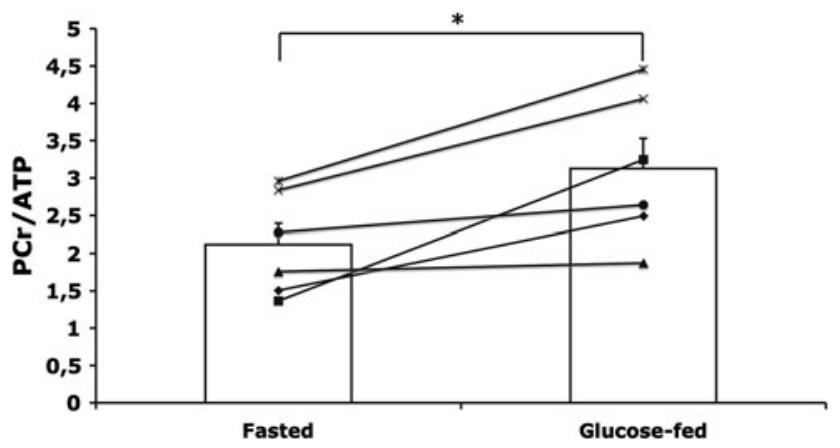

Fig. $4 \mathrm{PCr} / \mathrm{ATP}$ ratio $4 \mathrm{~h}$ post-exercise, $n=6$, $* p=0.014$. Data are depicted both as individual and mean $\pm \mathrm{SE}$

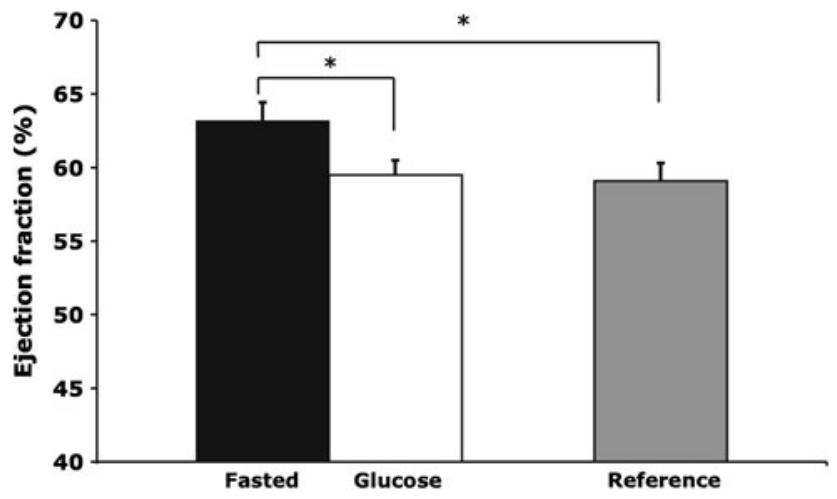

Fig. 5 Left ventricular ejection fraction $4 \mathrm{~h}$ post-exercise, with (white bar) and without (black bar) glucose ingestion, compared with a reference (gray bar) measurement. ${ }^{*} p<0.05$. Data are mean $\pm \mathrm{SE}$

the measurement in the fasted ( $52 \pm 4$ vs. $62 \pm 4 \mathrm{bpm}$, $n=9, p=0.001)$ and glucose-fed state $(52 \pm 4 \mathrm{bpm}$ $58 \pm 3 \mathrm{bpm}, n=9, p=0.013)$ at $4 \mathrm{~h}$ of recovery.

\section{Discussion}

The primary finding of the present study is that cardiac lipid content increases upon exercise-induced-i.e. physiological-elevation of plasma FA concentrations in healthy lean young men. Furthermore, we revealed that this increase in cardiac lipid content is paralleled by a lower cardiac energy status (lower PCr/ATP), but not by a lowered cardiac function. These results indicate that cardiac muscle is rather unrestricted in its uptake of circulating FA and that the validity of PCr/ATP ratio as a relevant marker of cardiac function can be debated under some circumstances.

There is an increasing prevalence of obesity worldwide, and obesity is well known to be an independent risk factor for the development of heart failure. Obesity is associated with excessive storage of lipids (triglycerides) not only in adipose tissue, but also in non-adipose tissues, such as the heart. We show here for the first time that cardiac lipid content is increased upon exercise-induced elevation of plasma FA concentrations in healthy lean young men, and that blunting of the exercise-induced increase in plasma FA concentrations completely prevents the increase in cardiac lipid content. This suggests that in healthy lean young men plasma FA concentration is an important determinant of cardiac lipid content, which in turn suggests that in this population uptake of FA in the heart largely depends on FA availability. This is in agreement with previous studies pointing at the importance of high FA concentrations as determinants of cardiac lipid content [5]. Increased cardiac lipid content is shown to be associated with obesity and diabetes $[5,26,30,32]$, conditions in which it is well known that plasma FA concentrations are high. Furthermore, fasting for more than $48 \mathrm{~h} \mathrm{[18]}$ or a very low calorie diet for more than 3 days [33], which both are characterized by elevated plasma FA concentrations, also resulted in increased cardiac lipid content. Although our results may suggest that elevated plasma FA concentrations may also underlie cardiac lipid accumulation and cardiac dysfunction in obesity and diabetes, it is important to note that major differences exist between obesity, insulin resistance and fasting. Thus, although both conditions are characterized by elevated plasma FA concentrations, plasma leptin and insulin levels are elevated in obesity, but markedly reduced upon fasting. It has recently been shown that under conditions of systemic insulin resistance the heart remains insulin sensitive [25]; therefore, chronic stimulation of multiple signaling processes in the myocardium by leptin and insulin may result in cardiac pathology.

Interestingly, our findings that elevated plasma FA lead to cardiac lipid accumulation are to some extent in accordance with observations in skeletal muscle. Thus, we have previously shown that during exercise, when peripheral lipolysis is stimulated to increase plasma FA availability for subsequent oxidation, a net accumulation of intramyocellular lipids occurred in non-exercising muscles of the upper arm, indicating that high circulatory FA concentrations also lead to unrestricted uptake of FA in skeletal muscle [24]. However, intramyocellular lipid content was reduced in the exercising muscles of the leg, suggesting that in this active muscle FA delivery was customized to FA oxidation. In that respect, it is surprising that in cardiac muscle, which heavily relies on FA for oxidation during exercise, the elevation of plasma FA lead to an increase rather than a decrease in cardiac lipid content. This suggests that the uptake of FA in cardiac muscle is less well-tuned to the oxidative needs compared to skeletal muscle and that even under conditions of increased cardiac work, FA entering the heart are shuttled towards storage rather than to oxidation.

In parallel to the increased cardiac lipid content, we also observed a lower cardiac energy status (lower PCr/ATP). 
Cardiac energy status has a strong prognostic value in heart failure patients, and it has been suggested to be an early marker of disturbed cardiac metabolism [16]. In line with this, Scheuermann-Freestone et al. [21] found that the PCr/ATP ratios correlate negatively with plasma FA concentrations. Furthermore, a decreased PCr/ATP ratio has been found to be associated with diastolic dysfunction and diabetes [19]. As an explanation for this finding, it has been suggested that plasma FA increase the expression of mitochondrial uncoupling proteins in the heart, and these proteins can reduce the efficiency with which mitochondria can produce ATP, thereby resulting in altered PCr/ATP ratios [12]. Some care should be taken when interpreting $\mathrm{PCr} / \mathrm{ATP}$ ratios as energy status, as the assumption that a decreased PCr/ATP ratio is reflecting a decreased $\mathrm{PCr} / \mathrm{Cr}$ ratio which can theoretically be biased by a decrease in total creatine concentration. In that context, other studies have shown that indeed creatine concentration in the failing heart is decreased [13, 14, 27]. In the current study, we cannot exclude that creatine depletion contributes to the lower PCr/ATP ratio found in the fasted condition.

However, even though an increased cardiac lipid content was associated with a lower cardiac energy status in the present study, the systolic cardiac function was not negatively affected. The systolic cardiac function was determined by multi-slice CINE-MRI, which is the gold standard for measuring systolic cardiac function. Together with myocardial spectroscopy, this permits examinations of associations between myocardial triglyceride concentrations and cardiac function. Surprisingly, cardiac function was higher in the condition with high plasma FA concentrations and elevated cardiac lipid content compared with the glucose-fed state. Moreover, cardiac function in the fasted state was in fact elevated when compared with the reference condition. Increased concentrations of adrenaline and noradrenaline may be underlying the stronger contraction in that case. Alternatively, changes in peripheral resistance may occur with the current protocol, which may affect ejection fraction. Although the exact mechanism explaining the increased cardiac function in the high plasma FFA condition remains speculative, we can conclude that, if anything, the elevated plasma FA concentrations and concomitant cardiac lipid content did not negatively impact cardiac function. This shows that at least in this population $\mathrm{PCr} /$ ATP ratio is not a good marker of cardiac function under acute conditions of elevated FA.

In summary, in this study, we revealed that elevated plasma FA concentrations, induced by prolonged exercise in the fasted state, increased storage of triglycerides in cardiac tissue, but did not acutely hamper systolic function. Although the lower cardiac energy status is in line with a lipotoxic action of cardiac lipids, a causal relationship cannot be proven, and it cannot be excluded that acute prolonged exercise influences cardiac energy status and lipid content independently.

Acknowledgments Dr. M. Schär kindly provided the navigator software used for the ${ }^{1} \mathrm{H}$-MRS measurements. Dr. P. Schrauwen is supported by a 'VICI' Research Grant for innovative research from the Netherlands Organization for Scientific Research (Grant 918.96.618). This research was supported by the Center for Translational Molecular Medicine and the Netherlands Heart Foundation, Dutch Diabetes Research Foundation and Dutch Kidney Foundation (PREDICCt).

Open Access This article is distributed under the terms of the Creative Commons Attribution Noncommercial License which permits any noncommercial use, distribution, and reproduction in any medium, provided the original author(s) and source are credited.

\section{References}

1. Cheng L, Ding G, Qin Q, Huang Y, Lewis W, He N, Evans RM, Schneider MD, Brako FA, Xiao Y, Chen YE, Yang Q (2004) Cardiomyocyte-restricted peroxisome proliferator-activated receptor-delta deletion perturbs myocardial fatty acid oxidation and leads to cardiomyopathy. Nat Med 10(11):1245-1250. doi: $10.1038 / \mathrm{nm} 1116$

2. Chiu HC, Kovacs A, Blanton RM, Han X, Courtois M, Weinheimer CJ, Yamada KA, Brunet S, Xu H, Nerbonne JM, Welch MJ, Fettig NM, Sharp TL, Sambandam N, Olson KM, Ory DS, Schaffer JE (2005) Transgenic expression of fatty acid transport protein 1 in the heart causes lipotoxic cardiomyopathy. Circ Res 96(2):225-233. doi:10.1161/01.RES.0000154079.20681.B9

3. Chiu HC, Kovacs A, Ford DA, Hsu FF, Garcia R, Herrero P, Saffitz JE, Schaffer JE (2001) A novel mouse model of lipotoxic cardiomyopathy. J Clin Invest 107(7):813-822. doi:10.1172/JCI10947

4. Hansch A, Rzanny R, Heyne JP, Leder U, Reichenbach JR, Kaiser WA (2005) Noninvasive measurements of cardiac highenergy phosphate metabolites in dilated cardiomyopathy by using 31P spectroscopic chemical shift imaging. Eur Radiol 15(2):319-323. doi:10.1007/s00330-004-2504-0

5. Kankaanpaa M, Lehto HR, Parkka JP, Komu M, Viljanen A, Ferrannini E, Knuuti J, Nuutila P, Parkkola R, Iozzo P (2006) Myocardial triglyceride content and epicardial fat mass in human obesity: relationship to left ventricular function and serum free fatty acid levels. J Clin Endocrinol Metab 91(11):4689-4695. doi: 10.1210/jc.2006-0584

6. Kenchaiah S, Evans JC, Levy D, Wilson PW, Benjamin EJ, Larson MG, Kannel WB, Vasan RS (2002) Obesity and the risk of heart failure. N Engl J Med 347(5):305-313

7. Kozerke S, Schar M, Lamb HJ, Boesiger P (2002) Volume tracking cardiac 31P spectroscopy. Magn Reson Med 48(2):380-384. doi: $10.1002 / \mathrm{mrm} .10182$

8. Kuipers H, Verstappen FT, Keizer HA, Geurten P, van Kranenburg G (1985) Variability of aerobic performance in the laboratory and its physiologic correlates. Int J Sports Med 6(4):197-201. doi: $10.1055 / \mathrm{s}-2008-1025839$

9. Lamb HJ, Doornbos J, den Hollander JA, Luyten PR, Beyerbacht HP, van der Wall EE, de Roos A (1996) Reproducibility of human cardiac 31P-NMR spectroscopy. NMR Biomed 9(5):217-227

10. Mokdad AH, Ford ES, Bowman BA, Dietz WH, Vinicor F, Bales VS, Marks JS (2003) Prevalence of obesity, diabetes, and obesityrelated health risk factors, 2001. JAMA 289(1):76-79. doi:10. 1001/jama.289.1.76 
11. Murphy NF, MacIntyre K, Stewart S, Hart CL, Hole D, McMurray JJ (2006) Long-term cardiovascular consequences of obesity: 20-year follow-up of more than 15000 middle-aged men and women (the Renfrew-Paisley study). Eur Heart J 27(1): 96-106. doi:10.1093/eurheartj/ehi506

12. Murray AJ, Anderson RE, Watson GC, Radda GK, Clarke K (2004) Uncoupling proteins in human heart. Lancet 364(9447): 1786-1788. doi:10.1016/S0140-6736(04)17402-3

13. Nakae I, Mitsunami K, Omura T, Yabe T, Tsutamoto T, Matsuo $\mathrm{S}$, Takahashi M, Morikawa S, Inubushi T, Nakamura Y, Kinoshita M, Horie M (2003) Proton magnetic resonance spectroscopy can detect creatine depletion associated with the progression of heart failure in cardiomyopathy. J Am Coll Cardiol 42(9):1587-1593. doi:10.1016/j.jacc.2003.05.005

14. Nakae I, Mitsunami K, Yoshino T, Omura T, Tsutamoto T, Matsumoto T, Morikawa S, Inubushi T, Horie M (2010) Clinical features of myocardial triglyceride in different types of cardiomyopathy assessed by proton magnetic resonance spectroscopy: comparison with myocardial creatine. J Card Fail 16(10): 812-822. doi:10.1016/j.cardfail.2010.05.006

15. Naressi A, Couturier C, Devos JM, Janssen M, Mangeat C, de Beer R, Graveron-Demilly D (2001) Java-based graphical user interface for the MRUI quantitation package. Magma 12(2-3): $141-152$

16. Neubauer S (2007) The failing heart-an engine out of fuel. N Engl J Med 356(11):1140-1151

17. Nielsen LB, Bartels ED, Bollano E (2002) Overexpression of apolipoprotein B in the heart impedes cardiac triglyceride accumulation and development of cardiac dysfunction in diabetic mice. J Biol Chem 277(30):27014-27020. doi:10.1074/jbc. M203458200

18. Reingold JS, McGavock JM, Kaka S, Tillery T, Victor RG, Szczepaniak LS (2005) Determination of triglyceride in the human myocardium by magnetic resonance spectroscopy: reproducibility and sensitivity of the method. Am J Physiol Endocrinol Metab 289(5):E935-E939. doi:10.1152/ajpendo.00095.2005

19. Rijzewijk LJ, Jonker JT, van der Meer RW, Lubberink M, de Jong HW, Romijn JA, Bax JJ, de Roos A, Heine RJ, Twisk JW, Windhorst AD, Lammertsma AA, Smit JW, Diamant M, Lamb HJ (2010) Effects of hepatic triglyceride content on myocardial metabolism in type 2 diabetes. J Am Coll Cardiol 56(3):225-233. doi:10.1016/j.jacc.2010.02.049

20. Roger VL, Weston SA, Redfield MM, Hellermann-Homan JP, Killian J, Yawn BP, Jacobsen SJ (2004) Trends in heart failure incidence and survival in a community-based population. JAMA 292(3):344-350. doi:10.1001/jama.292.3.344

21. Scheuermann-Freestone M, Madsen PL, Manners D, Blamire AM, Buckingham RE, Styles P, Radda GK, Neubauer S, Clarke K (2003) Abnormal cardiac and skeletal muscle energy metabolism in patients with type 2 diabetes. Circulation 107(24): 3040-3046. doi:10.1161/01.CIR.0000072789.89096.10

22. Schrauwen P, Hesselink MK, Vaartjes I, Kornips E, Saris WH, Giacobino JP, Russell A (2002) Effect of acute exercise on uncoupling protein 3 is a fat metabolism-mediated effect. Am J Physiol Endocrinol Metab 282(1):E11-E17

23. Schrauwen-Hinderling VB, Hesselink MK, Meex R, van der Made S, Schar M, Lamb H, Wildberger JE, Glatz J, Snoep G, Kooi ME, Schrauwen P (2010) Improved ejection fraction after exercise training in obesity is accompanied by reduced cardiac lipid content. J Clin Endocrinol Metab 95(4):1932-1938. doi: 10.1210/jc.2009-2076
24. Schrauwen-Hinderling VB, van Loon LJ, Koopman R, Nicolay $\mathrm{K}$, Saris WH, Kooi ME (2003) Intramyocellular lipid content is increased after exercise in nonexercising human skeletal muscle. J Appl Physiol 95(6):2328-2332. doi:10.1152/japplphysiol. 00304.2003

25. Schwarzer M, Britton SL, Koch LG, Wisloff U, Doenst T (2010) Low intrinsic aerobic exercise capacity and systemic insulin resistance are not associated with changes in myocardial substrate oxidation or insulin sensitivity. Basic Res Cardiol 105(3): 357-364. doi:10.1007/s00395-010-0087-2

26. Sharma S, Adrogue JV, Golfman L, Uray I, Lemm J, Youker K, Noon GP, Frazier OH, Taegtmeyer H (2004) Intramyocardial lipid accumulation in the failing human heart resembles the lipotoxic rat heart. FASEB J 18(14):1692-1700. doi:10.1096/fj. 04-2263com

27. Shen W, Asai K, Uechi M, Mathier MA, Shannon RP, Vatner SF, Ingwall JS (1999) Progressive loss of myocardial ATP due to a loss of total purines during the development of heart failure in dogs: a compensatory role for the parallel loss of creatine. Circulation 100(20):2113-2118

28. Siri WE (1956) The gross composition of the body. Adv Biol Med Phys 4:239-280

29. Szczepaniak LS, Babcock EE, Schick F, Dobbins RL, Garg A, Burns DK, McGarry JD, Stein DT (1999) Measurement of intracellular triglyceride stores by $\mathrm{H}$ spectroscopy: validation in vivo. Am J Physiol 276(5 Pt 1):E977-E989

30. Szczepaniak LS, Dobbins RL, Metzger GJ, Sartoni-D’Ambrosia G, Arbique D, Vongpatanasin W, Unger R, Victor RG (2003) Myocardial triglycerides and systolic function in humans: in vivo evaluation by localized proton spectroscopy and cardiac imaging. Magn Reson Med 49(3):417-423. doi:10.1002/mrm.10372

31. Unger RH, Orci L (2001) Diseases of liporegulation: new perspective on obesity and related disorders. FASEB J 15(2):312-321. doi:10.1096/fj.00-0590

32. van der Meer RW, Doornbos J, Kozerke S, Schar M, Bax JJ, Hammer S, Smit JW, Romijn JA, Diamant M, Rijzewijk LJ, de Roos A, Lamb HJ (2007) Metabolic imaging of myocardial triglyceride content: reproducibility of $1 \mathrm{H}$ MR spectroscopy with respiratory navigator gating in volunteers. Radiology 245(1): 251-257. doi:10.1148/radiol.2451061904

33. van der Meer RW, Hammer S, Smit JW, Frolich M, Bax JJ, Diamant M, Rijzewijk LJ, de Roos A, Romijn JA, Lamb HJ (2007) Short-term caloric restriction induces accumulation of myocardial triglycerides and decreases left ventricular diastolic function in healthy subjects. Diabetes 56(12):2849-2853. doi: $10.2337 / \mathrm{db} 07-0768$

34. Vanhamme L, van den Boogaart A, Van Huffel S (1997) Improved method for accurate and efficient quantification of MRS data with use of prior knowledge. J Magn Reson 129(1): 35-43. doi:10.1006/jmre.1997.1244

35. Yagyu H, Chen G, Yokoyama M, Hirata K, Augustus A, Kako Y, Seo T, Hu Y, Lutz EP, Merkel M, Bensadoun A, Homma S, Goldberg IJ (2003) Lipoprotein lipase (LpL) on the surface of cardiomyocytes increases lipid uptake and produces a cardiomyopathy. J Clin Invest 111(3):419-426. doi:10.1172/JCI16751

36. Zhou YT, Grayburn P, Karim A, Shimabukuro M, Higa M, Baetens D, Orci L, Unger RH (2000) Lipotoxic heart disease in obese rats: implications for human obesity. Proc Natl Acad Sci USA 97(4):1784-1789 